\title{
Feasibility Study of Sequentially Alternating EGFR-TKIs and Chemotherapy for Patients with Non-small Cell Lung Cancer
}

\author{
YOSHIZUMI TAKEMURA ${ }^{1}$, YUSUKE CHIHARA ${ }^{2}$, YOSHIE MORIMOTO $^{2}$, KEIKO TANIMURA $^{2}$, \\ TATSUYA IMABAYASHI ${ }^{2}$, YURIE SEKO $^{2}$, YOSHIKO KANEKO ${ }^{2}$, KOJI DATE $^{3}$, \\ MIKIO UEDA ${ }^{4}$, TAICHIRO ARIMOTO ${ }^{5}$, YOSHINOBU IWASAKI ${ }^{6}$ and KOICHI TAKAYAMA ${ }^{2}$ \\ ${ }^{1}$ Department of Pulmonary Medicine, Kyoto Kuramaguchi Medical Center, Kyoto, Japan; \\ ${ }^{2}$ Department of Pulmonary Medicine, Kyoto Prefectural University of Medicine, Kyoto, Japan; \\ ${ }^{3}$ Department of Pulmonary Medicine, Nantan General Hospital, Kyoto, Japan; \\ ${ }^{4}$ Department of Pulmonary Medicine, Nishijin Hospital, Kyoto, Japan; \\ ${ }^{5}$ Kyoto Kojo Hokenkai Clinic, Kyoto, Japan; \\ ${ }^{6}$ Department of Pulmonary Medicine, Showa General Hospital, Tokyo, Japan
}

\begin{abstract}
Background/Aim: The purpose of this trial was to evaluate the feasibility and efficacy of alternating platinum-based doublet chemotherapy with epidermal growth factor receptor tyrosine kinase inhibitors (EGFRTKIs) in patients with EGFR-mutant non-small cell lung cancer (NSCLC). Patients and Methods: Chemotherapynaive patients with advanced NSCLC harboring an EGFR mutation were enrolled. All patients underwent induction chemotherapy by sequentially alternating pemetrexed/ cisplatin/bevacizumab and EGFR-TKIs followed by maintenance therapy with pemetrexed/bevacizumab and EGFR-TKIs. The primary outcome was the completion rate of the induction therapy. Results: Eighteen eligible patients were enrolled between May 2011 and March 2016. The completion rate of induction therapy was $72.2 \%$ (13/18). Unfortunately, one patient developed grade 4 acute renal injury, but no other serious complications concerning this protocol were observed. Furthermore, diarrhea, rashes, and hematological adverse effects were mild. Conclusion: The completion rate of induction therapy was promising. Alternating chemotherapy and EGFR-TKIs should be further investigated regarding feasibility and efficacy.
\end{abstract}

Lung cancer is the leading cause of cancer-related death worldwide with more than 1 million deaths annually. Non-

Correspondence to: Dr. Koichi Takayama, Department of Pulmonary Medicine, Kyoto Prefectural University of Medicine, 465 Kawaramachi Hirokoji, Kamigyo-ku, Kyoto 602-8566, Japan. Tel: +81 752515513, e-mail: takayama@koto.kpu-m.ac.jp

Key Words: Alternating chemotherapy, non-small cell lung cancer, epidermal growth factor receptor tyrosine kinase inhibitor, pemetrexed. small cell lung cancer (NSCLC) accounts for about $80 \%$ of all lung cancers (1). A large number of clinical trials have found that the optimal chemotherapy regimen with cytotoxic agents for advanced NSCLC is platinum doublets, including the combination of platinum agents (cisplatin or carboplatin) and third-generation chemotherapy agents (paclitaxel, docetaxel, gemcitabine, and vinorelbine) (2-4). One study found that the outcomes of such platinum doublets are nearly identical and do not show sufficient improvement, resulting in $50-60 \%$ of patients with a one-year survival rate and 20$30 \%$ with a two-year survival rate (4).

Meanwhile, the efficacy of pemetrexed for nonsquamous NSCLC was investigated together with a subanalysis of a phase III, randomized study, which compared pemetrexed plus platinum and cisplatin plus gemcitabine (5). This sub-analysis revealed a significant survival advantage in the pemetrexed-treated group (overall survival (OS) 11.8 vs. 10.4 months, hazard ratio (HR) 0.81; $p=0.005$ ) and indicated a different efficacy profile of pemetrexed by histology. Based on this report, pemetrexed plus cisplatin is now recommended for non-squamous NSCLC by the National Comprehensive Cancer Network (NCCN) guidelines.

Bevacizumab, a monoclonal antibody against vascular endothelial growth factor, has been reported to be clinically beneficial, although attention to increased treatment-related adverse effects is required when it is added to platinum doublets. Sandler et al. found longer OS (12.3 vs. 10.3 months, $\mathrm{HR}=0.79 ; p=0.003)$ and progression-free survival (PFS) (6.2 vs. 4.5 months, $\mathrm{HR}=0.66 ; p<0.001)$ when bevacizumab is added to paclitaxel and carboplatin (6). Reck et al. have also reported an extended PFS, but no change in the OS, when bevacizumab was combined with cisplatin plus gemcitabine (7). 
With regard to maintenance therapy, a phase III clinical study of continuation maintenance after platinum-based chemotherapy showed an extended PFS (4.3 vs. 2.6 months, HR $0.50 ; p<0.001)$ and OS (13.4 vs. 10.6 months, HR 0.79; $p=0.0012)$ in the pemetrexed-treated group compared with those in the placebo group for non-squamous NSCLC (8). Therefore, continuation maintenance with pemetrexed after four cycles of cisplatin plus pemetrexed until progressive disease (PD) will be clinically beneficial presumably due to its favorable safety profile. In addition to pemetrexed, a combination with bevacizumab is also a preferred method for maintenance. A phase II clinical study on continuation maintenance following carboplatin plus pemetrexed and bevacizumab demonstrated preferable PFS (7.8 months, $95 \%$ confidence interval $(\mathrm{CI})=5.2-11.5$ months $)$ and OS $(14.1$ months, 95\% CI=10.8-19.6 months) with an acceptable toxicity for non-squamous NSCLC (9).

The efficacy of epidermal growth factor receptor tyrosine kinase inhibitors (EGFR-TKIs) is much higher than that of platinum doublets in the treatment of NSCLC in patients with a sensitive EGFR mutation. All phase III trials targeted against EGFR mutations demonstrated prolonged PFS in the EGFR-TKIs group. However, a significant difference in the OS has not been reported to date (10-15). Therefore, EGFRTKIs are now considered essential for patients with EGFRmutant NSCLC to be administered at least once unless contraindicated.

It is important to explore optimal strategies for chemotherapy using the available arms. A fundamental idea of chemotherapy, based on the Goldie-Coldman hypothesis (16), is that a combination of multiple noncross-resistant agents works efficiently to inhibit cell growth. Therefore, EGFR-TKIs and platinum doublets should be administered in combination. Studies have verified the synergic benefit of concomitant combination therapy by EGFR-TKIs and platinum doublets for NSCLC $(17,18)$. However, to the best of our knowledge, no significant benefits have been reported, because many patients with NSCLC expressing wild-type EGFR were presumably included in the studies.

Additional benefits were not shown with the concomitant combination therapy possibly due to the different anti-tumor mechanisms of the two types of agents. Most cytotoxic agents cause S-phase arrest, whereas EGFR-TKIs cause $\mathrm{G}_{1^{-}}$ phase arrest. Moreover, in vitro experiments have been shown to support the idea, that alternating the drug application inhibits cell growth more efficiently than the simultaneous application based on different cell cycle phases where cytotoxic agents and EGFR-TKIs interfere (19).

Based on this background, we conducted a feasibility study to evaluate a sequentially alternating chemotherapy using EGFR-TKIs and platinum doublets followed by maintenance therapy.

\section{Patients and Methods}

Study design. This clinical trial was conducted to evaluate the feasibility, efficacy, and safety of sequentially alternating chemotherapy for patients with advanced NSCLC and an EGFR mutation. The primary endpoint of this study was the completion rate of the induction therapy. Secondary outcomes were the response rate, disease control rate, PFS, one-year survival rate, safety, and OS.

This study was conducted in accordance with the declaration of Helsinki. The protocol was reviewed and approved by the Kyoto Prefectural University of Medicine Institutional Review Board. Written informed consent was obtained from all patients. The clinical trial registration number was UMIN000005917.

Eligibility. Patients aged 20 to 70 years with Stage IV or postoperative recurrent NSCLC with an EGFR mutation were eligible. The other inclusion criteria were as follows: (1) chemotherapy-naive patients including postoperative adjuvant chemotherapy, (2) Eastern Cooperative Oncology Group performance status of 0 or 1, (3) existence of at least one measurable region of disease, and (4) no major organ disorders as indicated by a neutrophil count $\geq 2,000 / \mu 1$, hemoglobin $\geq 9.5 \mathrm{~g} / \mathrm{dl}$, platelet count $\geq 100,000 / \mu \mathrm{l}$, aspartate aminotransferase (AST) and alanine aminotransferase (ALT) levels $\leq 2.5 \mathrm{x}$ the upper limit of normal, serum albumin level $\geq 2.5 \mathrm{~g} / \mathrm{dl}$, serum creatinine level $\leq 1.2 \mathrm{mg} / \mathrm{dl}$, total bilirubin level $\leq 1.5 \mathrm{x}$ the upper limit of normal, and oxygen saturation by pulse oximetry $\geq 92 \%$, (5) and a life expectancy longer than 90 days.

Patients were excluded if histology of the lung cancer showed squamous cell carcinoma, progressive interstitial pneumonia shown by a chest X-ray, uncontrollable fluid accumulation, concomitant malignancy, metastasis in the central nervous system, history of hemoptysis (reoccurring or needing medical care), or visible cavity lesions. Patients with any manifestation of cardiac complications such as heart failure, arrhythmia, or ischemic heart disease (within six months) that needed medical care were excluded.

Study treatment. Induction therapy: Eligible patients were given cytotoxic chemotherapy on day 1 consisting of $500 \mathrm{mg} / \mathrm{m}^{2}$ pemetrexed and $75 \mathrm{mg} / \mathrm{m}^{2}$ cisplatin intravenously, in combination with $15 \mathrm{mg} / \mathrm{kg}$ bevacizumab unless contraindicated. Then EGFRTKIs (either gefitinib or erlotinib) were given from day 22 to 42 . The six-week regimen consisted of two different arms given alternately in a cycle. Induction therapy was designed to be repeated up to four cycles.

Continuation maintenance therapy: After completion of the induction therapy, patients underwent a continuation maintenance therapy until the advent of PD or until they met the criteria for discontinuation. In the maintenance phase, patients were treated with $500 \mathrm{mg} / \mathrm{m}^{2}$ pemetrexed on day 1 in combination with $15 \mathrm{mg} / \mathrm{kg}$ bevacizumab, if applicable, and EGFR-TKIs (either gefitinib or erlotinib) from day 22 to 42 . One cycle consisted of two different arms given alternately and repeated every six weeks. The schema of the chemotherapy protocol is shown in brief in Figure 1.

Assessment of efficacy and safety. Toxicities were evaluated according to the National Cancer Institute Common Toxicity Criteria for Adverse Events, Version 4.0. Complete blood counts and serum chemistries were assessed before registry, frequently in the first cycle, and on day 1 and 22 of each cycle. The tumor response to chemotherapy was assessed according to the Response Evaluation 


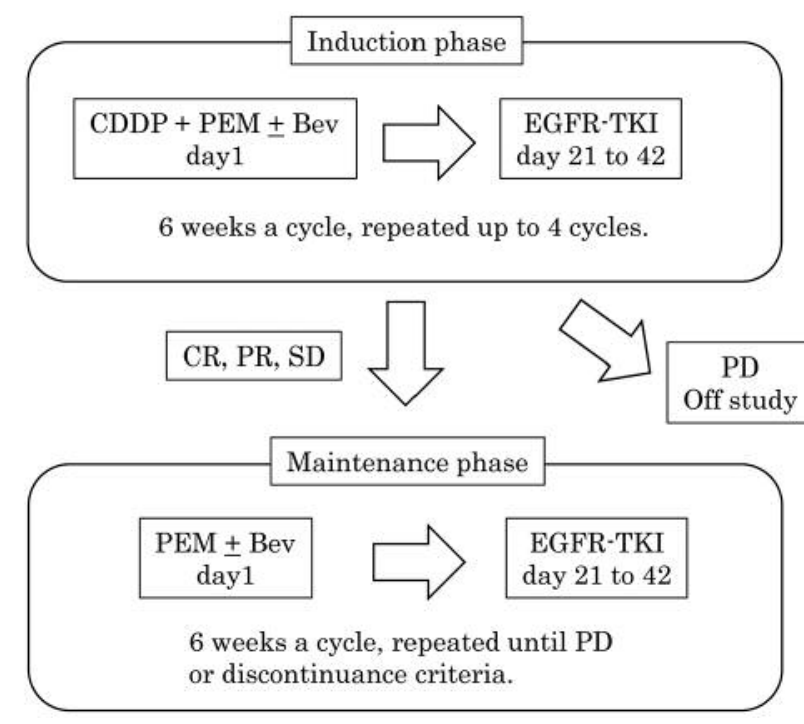

Figure 1. Schema of study protocol. CDDP: Cisplatin; PEM: pemetrexed; Bev: bevacizumab.

Criteria in Solid Tumors, version 1.1. After the baseline evaluation, the tumor response status was assessed every six weeks. The PFS was defined as the period between enrollment and the day disease progression was confirmed. The OS was defined as the period of study enrollment to death. Patients alive at the end of follow-up were censored.

Statistical analysis. A one-stage design using binominal probability was used to determine the sample size. Assuming that a response rate of $80 \%$ would be expected, whereas a rate of $50 \%$ would be the lower limit of interest. The estimated number of patients for accrual was 19 for $\alpha=0.05$ (one-sided) and $\beta=0.2$. After assuming an inevaluability rate of $<10 \%$, we planned to accrue 21 patients. The PFS and OS were calculated using the Kaplan-Meier method.

Ethical approval. All procedures performed in studies involving human participants were in accordance with the ethical standards of the institutional committee and with the 1964 Helsinki declaration and its later amendments or comparable ethical standards. Written informed consent was obtained from all participants included in the study.

\section{Results}

Patient's characteristics. From May 2011 to March 2016, 18 patients with Stage IIB/IV non-squamous NSCLC were enrolled in the study. The patients characteristics are shown in Table I. There were nine females and nine males, with a median age of 66.5 years ranging from 43 to 77 . The number of patients with an exon 19 deletion, L858R, L861Q, and L858R/T790M mutation was nine, seven, one, and one, respectively. Five patients were eligible for bevacizumab. As a consequence, erlotinib was dominantly prescribed among the enrolled participants.
Table I. Patients characteristics $(n=18)$

\begin{tabular}{lc}
\hline Category & $\mathrm{N}$ \\
\hline Gender & \\
Female & 9 \\
Male & 9 \\
Median age (range), yr & $66.5(43-77)$ \\
Smoking history & \\
Ex or current smoker & 12 \\
never smoker & 6 \\
Performance status & \\
0 & 11 \\
1 & 7 \\
Histology cStage & \\
Adenocarcinoma & 18 \\
IIb & 1 \\
IV & 17 \\
EGFR mutation & \\
Ex19 del & 9 \\
L858R & 7 \\
L861Q & 1 \\
L858R+T790M & 1 \\
Chemo Regimen & \\
CDDP+PEM+Bev & 5 \\
CDDP+PEM & 13 \\
EGFR-TKI & 3 \\
Gefitinib & 15 \\
Erlotinib & \\
\hline
\end{tabular}

Outcomes. The median number of the chemotherapy cycles was five. The completion rate of the induction therapy was $72.2 \%$ (13/18). After completion of induction therapy, three patients withdrew from this study before PD according to their wishes, and they continued treatment with EGFR-TKIs. Thirteen patients entered into the maintenance phase with sequentially alternating chemotherapy by pemetrexed plus bevacizumab and EGFR-TKIs. The median number of the maintenance chemotherapy cycles was three.

A summary of the overall response is shown in Table II. The response rate was $61.1 \%(11 / 18)$, the disease control rate was $94.4 \%(17 / 18)$, and the one-year survival rate was $75.6 \%$ (13/17). The median PFS was 320 days (95\% CI=230733 days) and the median OS was 733 days $(98 \% \mathrm{CI}=344-$ 1544 days). A Kaplan-Meier curve of the PFS and OS are shown in Figures 2 and 3, respectively.

Safety and toxicity. The toxicity profile is summarized in Table III. Grade 3 or 4 toxicities were shown by leukopenia $(22.2 \%)$, neutropenia $(22.2 \%)$, thrombopenia $(5.6 \%)$, nausea $(5.6 \%)$, acute kidney injury (16.7\%), and depression (5.6\%) in the induction treatment phase. Unfortunately, one patient developed grade 4 acute renal injury that was presumably due to the cisplatin treatment. In general, diarrhea, rashes, and hematological adverse effects were milder than expected. 
Table II. Overall response.

\begin{tabular}{lrr}
\hline & $\mathrm{n}$ & $\%$ \\
\hline Complete response & 0 & 0.0 \\
Partial response & 11 & 61.1 \\
Stable disease & 6 & 33.3 \\
Disease control rate & 17 & 94.4 \\
Progressive disease & 0 & 0.0 \\
NE & 1 & 5.6 \\
\hline Total & 18 & \\
\hline
\end{tabular}

Table III. Toxicities $(n=18)$.

\begin{tabular}{lccc}
\hline Toxicity & Grade 2 (n) & Grade 3 (n) & Grade 4 (n) \\
\hline Hematologic & & & \\
Leukopenia & 6 & 3 & 1 \\
Neutropenia & 7 & 3 & 1 \\
Thrombopenia & 0 & 1 & 0 \\
Febrile Neutropenia & NA & 0 & 0 \\
Non-hematologic & & & \\
Nausea & 3 & 1 & 0 \\
Pigmentation & 1 & 0 & 0 \\
Diarrhea & 1 & 0 & 0 \\
Alopecia & 1 & 0 & 0 \\
Paronychia & 1 & 0 & 0 \\
Acute kidney injury & 0 & 2 & 1 \\
Rash & 3 & 0 & 0 \\
Depression & 0 & 1 & 0 \\
\hline
\end{tabular}

\section{Discussion}

The benefits of an extended OS have not been reported, although extended PFS have been suggested through sequential therapy with both cytotoxic agents and EGFRTKIs when compared with gefitinib monotherapy $(10,11)$ However, any combination therapy with EGFR-TKI treatment has the drawback of an eventually acquired resistance of tumor cells to EGFR-TKIs during treatment.

Mok et al. were the first to report a placebo-controlled, phase II clinical trial of alternating chemotherapy with cytotoxic agents and EGFR-TKIs. Although patients were enrolled regardless if they had an EGFR mutation or not, the authors concluded that the sequential administration of erlotinib following gemcitabine/platinum chemotherapy significantly improved PFS (29.4 vs. 23.4 weeks, HR 0.47; $p<0.01$ ) (20). Meanwhile, Cesare et al. reported a phase II randomized trial in the second-line setting for patients with squamous NSCLC; although it was prematurely interrupted, the

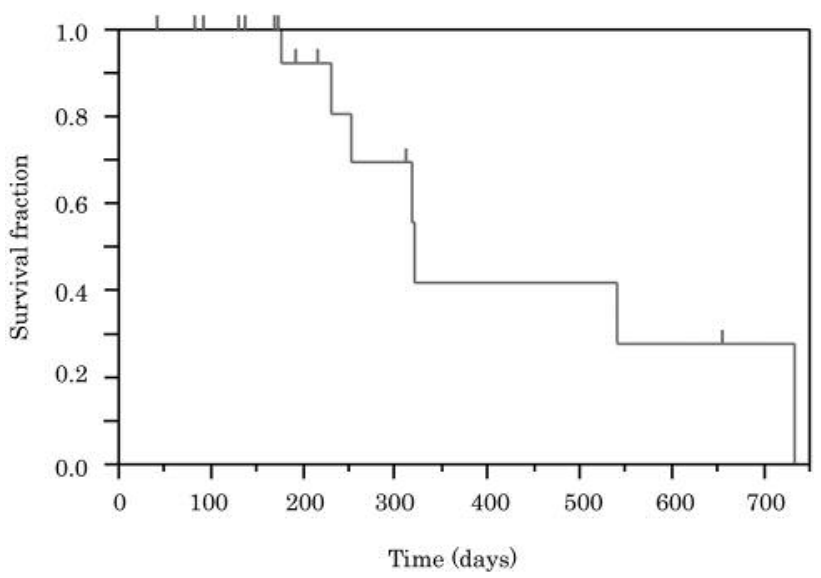

Figure 2. Progression-free survival (Kaplan-Meier curve). Median PFS was 320 days $(95 \%$ CI=230-733).

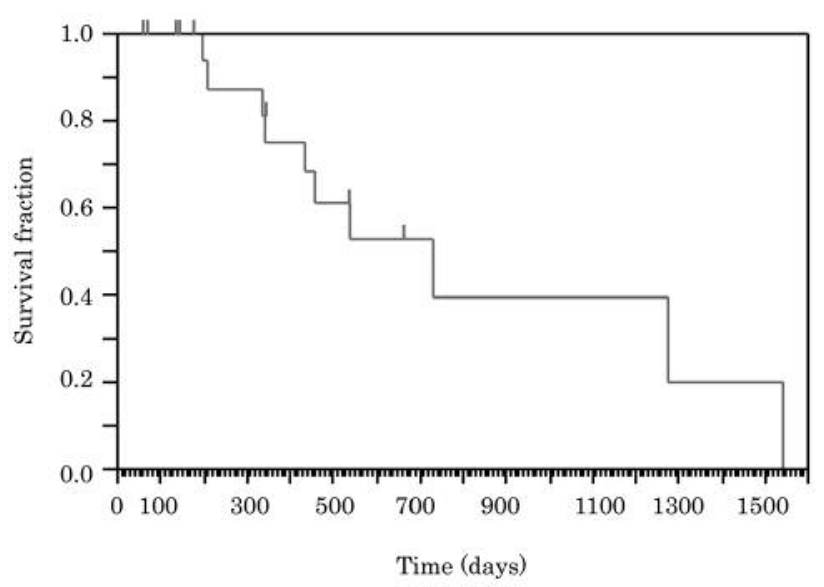

Figure 3. Overall survival (Kaplan-Meier curve). Median OS was 733 days $(98 \% C I=344-1544)$.

intermittent erlotinib plus docetaxel combination therapy was not efficacious (21). Thus, for better outcomes, patients should be appropriately selected for the combination therapy involving EGFR-TKIs.

Among these clinical trials, to the best of our knowledge, NEJ005/TCOG0902 is the only one that investigated a sequentially alternating therapy targeted at patients with tumor cells positive for EGFR mutations (22). They compared the PFS between concurrent and sequential alternating regimens. Their concurrent regimen consisted of concomitant gefitinib and carboplatin/pemetrexed on day 1 in a three-week cycle for up to six cycles, followed by concurrent gefitinib and pemetrexed maintenance until PD. Their sequentially alternating regimen consisted of eight weeks of gefitinib and then two cycles of carboplatin/ 
pemetrexed. The sequential treatment was repeated three times, followed by alternating gefitinib and pemetrexed for maintenance. As a result, both the concurrent and sequential alternating regimen demonstrated preferable PFS (18.3 vs. 15.3 months, HR $0.71 ; p=0.20$ ) with manageable toxicities. They also found that the concurrent regimen could be more advantageous regarding the OS (41.9 vs. 30.7 months, HR $0.51 ; p=0.042$ ). In addition, they noted that $41.5 \%$ of the patients in the concurrent regimen group required a dose reduction of carboplatin/pemetrexed, suggesting a noteworthy increase in hematological toxicity.

Our clinical study is similar to the NEJ005/TCOG0902 trial although we investigated a higher frequency of therapy rotation. One cycle consisted of three weeks of EGFR-TKIs and three weeks of chemotherapy. The optimal term of rotation remains unknown, but one can possibly be deduced according to the data from the in vitro experimental report (19).

The primary endpoint of this study was the completion rate of the induction therapy, which was $72.2 \%(13 / 18)$. Induction of the alternating therapy was shown to be feasible. The secondary endpoint for the overall response rate $(61.1 \%)$ appears to be practical. The PFS was longer than that from the cisplatin/pemetrexed/bevacizumab regimen and similar to that from gefitinib monotherapy regardless of the intermittent administration of EGFR-TKIs in this trial. The OS could not be reported on at the end of this study.

In clinical practice, conducting a sequentially alternating therapy with two arms is a long-term regimen that is laborintensive. However, rotating two arms with different profiles of adverse effects provides patients time to recover from them. This could be why diarrhea, rashes, and hematological adverse effects were milder than expected. Therefore, this kind of rotation deserves consideration for patients who suffer from severe adverse effects, such as rashes or anemia, from either EGFR-TKIs or platinum doublets so they can continue chemotherapy.

Three patients withdrew from the study before PD in the maintenance phase. In those cases, attending physicians and patients were aware of the long-term effectiveness of the EGFR-TKIs and decreased effectiveness of pemetrexed/ bevacizumab over time. There is a discrepancy between the periods of effectiveness, which come from the different PFS of the two arms. This is an essential issue for feedback on the management of alternating chemotherapy.

This feasibility study demonstrated that a sequentially alternating therapy with the combined administration of EGFR-TKIs and chemotherapy for NSCLC is practical. Efficacy should be further evaluated in a more extensive randomized study.

In conclusion, the completion rate of induction therapy was favorable, and the toxicities were mild. Overall, the feasibility of this study met our expectations.

\section{Conflicts of Interest}

Koichi Takayama received speaker honoraria from Chugai Pharmaceutical Co., Eli Lilly Co., Ono Pharmaceutical Co., Astrazeneca Co. and Boehringer-Ingelheim Co.. The other authors have no conflicts to declare.

\section{Acknowledgements}

The Authors acknowledge the contribution of all patients, care givers, and the staff involved in this study. This clinical trial was founded by Chugai Pharmaceutical Co. and Kyoto Prefectural University of Medicine.

\section{References}

1 Esposito L, Conti D, Ailavajhala R, Khalil $\mathrm{N}$ and Giordano A: Lung Cancer: Are we up to the Challenge? Curr Genomics 11: 513-518, 2010.

2 Schiller JH, Harrington D, Belani CP, Langer C, Sandler A, Krook J, Zhu J, Johnson DH and Eastern Cooperative Oncology Group: Comparison of four chemotherapy regimens for advanced nonsmall-cell lung cancer. N Engl J Med 346: 92-98, 2002.

3 Scagliotti GV, De Marinis F, Rinaldi M, Crinò L, Gridelli C, Ricci S, Matano E, Boni C, Marangolo M, Failla G, Altavilla G, Adamo V, Ceribelli A, Clerici M, Di Costanzo F, Frontini L, Tonato $\mathrm{M}$ and Italian Lung Cancer Project: Phase III randomized trial comparing three platinum-based doublets in advanced nonsmall-cell lung cancer. J Clin Oncol 20: 4285-4291, 2002.

4 Ohe Y, Ohashi Y, Kubota K, Tamura T, Nakagawa K, Negoro S, Nishiwaki Y, Saijo N, Ariyoshi Y and Fukuoka M: Randomized phase III study of cisplatin plus irinotecan versus carboplatin plus paclitaxel, cisplatin plus gemcitabine, and cisplatin plus vinorelbine for advanced non-small-cell lung cancer: Four-Arm Cooperative Study in Japan. Ann Oncol 18: 317-323, 2007.

5 Scagliotti GV, Parikh P, von Pawel J, Biesma B, Vansteenkiste J, Manegold C, Serwatowski P, Gatzemeier U, Digumarti R, Zukin M, Lee JS, Mellemgaard A, Park K, Patil S, Rolski J, Goksel T, de Marinis F, Simms L, Sugarman KP and Gandara D: Phase III study comparing cisplatin plus gemcitabine with cisplatin plus pemetrexed in chemotherapy-naive patients with advanced-stage non-small-cell lung cancer. J Clin Oncol 26: 3543-3551, 2008.

6 Sandler A, Gray R, Perry MC, Brahmer J, Schiller JH, Dowlati A, Lilenbaum R and Johnson DH: Paclitaxel-carboplatin alone or with bevacizumab for non-small-cell lung cancer. N Engl J Med 355: 2542-2550, 2006.

7 Reck M, von Pawel J, Zatloukal P, Ramlau R, Gorbounova V, Hirsh V, Leighl N, Mezger J, Archer V, Moore N, Manegold C and BO17704 Study Group: Overall survival with cisplatin-gemcitabine and bevacizumab or placebo as first-line therapy for nonsquamous non-small-cell lung cancer: results from a randomised phase III trial (AVAiL). Ann Oncol 21: 1804-1809, 2010.

8 Ciuleanu T, Brodowicz T, Zielinski C, Kim JH, Krzakowski M, Laack E, Wu YL, Bover I, Begbie S, Tzekova V, Cucevic B, Pereira JR, Yang SH, Madhavan J, Sugarman KP, Peterson P, John WJ, Krejcy K and Belani CP: Maintenance pemetrexed plus best supportive care versus placebo plus best supportive care for non-small-cell lung cancer: a randomised, double-blind, phase 3 study. Lancet 374: 1432-1440, 2009. 
9 Patel JD, Hensing TA, Rademaker A, Hart EM, Blum MG, Milton DT and Bonomi PD: Phase II study of pemetrexed and carboplatin plus bevacizumab with maintenance pemetrexed and bevacizumab as first-line therapy for nonsquamous non-smallcell lung cancer. J Clin Oncol 27: 3284-3289, 2009.

10 Mitsudomi T, Morita S, Yatabe Y, Negoro S, Okamoto I, Tsurutani J, Seto T, Satouchi M, Tada H, Hirashima T, Asami K, Katakami N, Takada M, Yoshioka H, Shibata K, Kudoh S, Shimizu E, Saito $\mathrm{H}$, Toyooka S, Nakagawa $\mathrm{K}$, Fukuoka $\mathrm{M}$ and West Japan Oncology Group: Gefitinib versus cisplatin plus docetaxel in patients with non-small-cell lung cancer harbouring mutations of the epidermal growth factor receptor (WJTOG3405): an open label, randomised phase 3 trial. Lancet Oncol 11: 121-128, 2010.

11 Maemondo M, Inoue A, Kobayashi K, Sugawara S, Oizumi S, Isobe $\mathrm{H}$, Gemma A, Harada M, Yoshizawa H, Kinoshita I, Fujita Y, Okinaga S, Hirano H, Yoshimori K, Harada T, Ogura T, Ando M, Miyazawa H, Tanaka T, Saijo Y, Hagiwara K, Morita S, Nukiwa T and North-East Japan Study Group: Gefitinib or chemotherapy for non-small-cell lung cancer with mutated EGFR. N Eng1 J Med 362: 2380-2388, 2010.

12 Zhou C, Wu YL, Chen G, Feng J, Liu XQ, Wang C, Zhang S, Wang J, Zhou S, Ren S, Lu S, Zhang L, Hu C, Hu C, Luo Y, Chen L, Ye M, Huang J, Zhi X, Zhang Y, Xiu Q, Ma J, Zhang L and You C: Erlotinib versus chemotherapy as first-line treatment for patients with advanced EGFR mutation-positive non-smallcell lung cancer (OPTIMAL. CTONG-0802): a multicentre, open-label, randomised phase 3 study. Lancet Oncol 12: 735742, 2011

13 Rosell R, Carcereny E, Gervais R, Vergnenegre A, Massuti B, Felip E, Palmero R, Garcia-Gomez R, Pallares C, Sanchez JM, Porta R, Cobo M, Garrido P, Longo F, Moran T, Insa A, De Marinis F, Corre R, Bover I, Illiano A, Dansin E, de Castro J, Milella M, Reguart N, Altavilla G, Jimenez U, Provencio M, Moreno MA, Terrasa J, Muñoz-Langa J, Valdivia J, Isla D, Domine M, Molinier O, Mazieres J, Baize N, Garcia-Campelo R, Robinet G, Rodriguez-Abreu D, Lopez-Vivanco G, Gebbia V, Ferrera-Delgado L, Bombaron P, Bernabe R, Bearz A, Artal A, Cortesi E, Rolfo C, Sanchez-Ronco M, Drozdowskyj A, Queralt C, de Aguirre I, Ramirez JL, Sanchez JJ, Molina MA, Taron M, Paz-Ares L and Spanish Lung Cancer Group in collaboration with Groupe Français de Pneumo-Cancérologie and Associazione Italiana Oncologia Toracica: Erlotinib versus standard chemotherapy as first-line treatment for European patients with advanced EGFR mutation-positive non-small-cell lung cancer (EURTAC): a multicentre, open-label, randomised phase 3 trial. Lancet Oncol 13: 239-246, 2012.

14 Sequist LV, Yang JC, Yamamoto N, O’Byrne K, Hirsh V, Mok T, Geater SL, Orlov S, Tsai CM, Boyer M, Su WC, Bennouna J, Kato T, Gorbunova V, Lee KH, Shah R, Massey D, Zazulina V, Shahidi M and Schuler M: Phase III study of afatinib or cisplatin plus pemetrexed in patients with metastatic lung adenocarcinoma with EGFR mutations. J Clin Oncol 31: 3327-3334, 2013.
15 Wu YL, Zhou C, Hu CP, Feng J, Lu S, Huang Y, Li W, Hou M, Shi JH, Lee KY, Xu CR, Massey D, Kim M, Shi Y and Geater SL: Afatinib versus cisplatin plus gemcitabine for first-line treatment of Asian patients with advanced non-small-cell lung cancer harbouring EGFR mutations (LUX-Lung 6): an openlabel, randomised phase 3 trial. Lancet Oncol 15: 213-222, 2014.

16 Goldie JH, Coldman AJ and Gudauskas GAL: Rationale for the use of alternating non-cross-resistant chemotherapy. Cancer Treat Rep 66: 439-449, 1982.

17 Giaccone G, Herbst RS, Manegold C, Scagliotti G, Rosell R, Miller V, Natale RB, Schiller JH, Von Pawel J, Pluzanska A, Gatzemeier U, Grous J, Ochs JS, Averbuch SD, Wolf MK, Rennie P, Fandi A and Johnson DH: Gefitinib in combination with gemcitabine and cisplatin in advanced non-small-cell lung cancer: a phase III trial--INTACT 1. J Clin Oncol 22: 777-784, 2004.

18 Herbst RS, Giaccone G, Schiller JH, Natale RB, Miller V, Manegold C, Scagliotti G, Rosell R, Oliff I, Reeves JA, Wolf MK, Krebs AD, Averbuch SD, Ochs JS, Grous J, Fandi A and Johnson DH: Gefitinib in combination with paclitaxel and carboplatin in advanced non-small-cell lung cancer: a phase III trial--INTACT 2. J Clin Oncol 22: 785-794, 2004.

$19 \mathrm{Li} \mathrm{T}$, Ling YH, Goldman ID and Perez-Soler R: Scheduledependent cytotoxic synergism of pemetrexed and erlotinib in human non-small cell lung cancer cells. Clin Cancer Res 13: 3413-3422, 2007.

20 Mok TS, Wu YL, Yu CJ, Zhou C, Chen YM, Zhang L, Ignacio J, Liao M, Srimuninnimit V, Boyer MJ, Chua-Tan M, Sriuranpong V, Sudoyo AW, Jin K, Johnston M, Chui W and Lee JS: Randomized, placebo-controlled, phase II study of sequential erlotinib and chemotherapy. J Clin Oncol 27: 5080-5087, 2009.

21 Gridelli C, Chella A, Valmadre G, Allegrini G, Brighenti M, Bidoli P, Rossi A, Maione P, Migliorino MR, Ricciardi S and DE Marinis F: Second-line erlotinib or intermittent erlotinib plus docetaxel in male ex-smokers with squamous NSCLC: The TALISMAN randomized trial. Anticancer Res 36: 6535-6540, 2016.

22 Sugawara S, Oizumi S, Minato K, Harada T, Inoue A, Fujita Y, Maemondo M, Yoshizawa H, Ito K, Gemma A, Nishitsuji M, Harada M, Isobe $\mathrm{H}$, Kinoshita I, Morita S, Kobayashi K, Hagiwara K, Kurihara M, Nukiwa T, North East Japan Study Group and Tokyo Cooperative Oncology Group: Randomized phase II study of concurrent versus sequential alternating gefitinib and chemotherapy in previously untreated non-small cell lung cancer with sensitive EGFR mutations: NEJ005/TCOG0902. Ann Oncol 26: 888-894, 2015.

Received January 26, 2018

Revised February 19, 2018 Accepted February 20, 2018 